\title{
European National Healthy City Networks: the Impact of an Elite Epistemic Community
}

\author{
Zoë Heritage and Geoff Green
}

\begin{abstract}
National healthy cities networks (NNs) were created 20 years ago to support the development of healthy cities within the WHO Europe Region. Using the concept of epistemic communities, the evolution and impact of NNs is considered, as is their future development. Healthy cities national networks are providing information, training and support to member cities. In many cases, they are also involved in supporting national public health policy development and disseminating out healthy city principles to other local authorities. National networks are a fragile but an extremely valuable resource for sharing public health knowledge.
\end{abstract}

KEYWORDS Healthy cities, Networks, Europe, WHO, Health determinants

\section{CONTEXT AND CONCEPTS}

In her review of the evolution and adoption of the Ottawa Charter on Health Promotion, Kickbusch ${ }^{1}$ refers to the contribution of the World Health Organization (WHO) to a new paradigm of public health. She recognises specifically the influence of an epistemic, transnational community of public health experts employed or commissioned by WHO. This article analyses an enlargement of this knowledge community via the National Networks of Healthy Cities and its role in influencing the policy communities of European cities. We build upon our evaluation of earlier phases of the WHO European Healthy Cities Networks ${ }^{2}$ and focus here on phase IV from 2003 to 2008.

In his influential article, $\mathrm{Haas}^{3}$ defined four unifying characteristics of an epistemic community; in summary, (1) normative principled beliefs, (2) shared causal beliefs about problems and their solutions, (3) shared notions of validity of evidence, and (4) a common policy enterprise to change practice with a concern that human welfare will be enhanced. WHO coordinates such an 'elite' epistemic community ${ }^{4}$ which brings together highly skilled professionals who work with other global experts, to carry out health research and to identify common policy approaches and responses based on a shared understanding of public health. Member states vest authority in WHO to undertake the five main roles summarised in HEALTH $21:^{5}$ 'act as a health conscience', 'function as a major information centre', 'promote the health for all policy', 'provide up-to-date evidence-based tools' and work as a 'catalyst for action.' Traditionally, WHO undertakes these roles with national governments via their ministries of health.

Heritage is with the French Healthy City Network, School of Public Health (EHESP), Rennes, France; Green is with the Sheffield Hallam University, Sheffield, UK.

Correspondence: Zoë Heritage, French Healthy City Network, School of Public Health (EHESP), Rennes, France. (E-mail: zh@villes-sante.com) 
However, Kickbusch, ${ }^{1}$ a leading WHO actor during the period of the Ottowa Charter and HEALTH21, describes how the WHO Regional Office for Europe developed a 'settings' approach, to 'transfer knowledge regarding what creates health and how to organize collective learning regarding how to improve health as an overall systems goal, not just the responsibility of the health sectors' (p. 386). The conceptual underpinning of this approach is that health is largely determined by economic context, and contexts (schools, prisons or whole cities) can be changed by good governance and salutogenic investment. Healthy cities has embraced this conceptual underpinning within a local democratic process involving the direct participation of politicians-across party lines-with a strong focus on community participation. ${ }^{6}$

Given modest resources but an ambition to diffuse knowledge widely to many agencies with a direct or indirect influence in a multitude of settings, the WHO European Office devised a 'new dissemination strategy through networks'. According to Kickbusch (p. 385), these were to be 'networks of commitment and diffusion.' In Europe, the first to be initiated, in 1987 for an initial phase of 5 years, was a modest network of 11 Healthy Cities. In parallel to the core European Healthy Cities Network supported directly by WHO, national networks (NN) of healthy cities quickly developed organically (and somewhat 'independently' according to a WHO review $)^{7}$ in many European countries. Within a year of the launch of the pilot cities network by WHO, national networks had linked together 200 cities in six countries. ${ }^{8}$ This expansion is in part attributable to an enlargement of the epistemic community at local, national and pan-European levels. NNs were initiated with the aim to help cities exchange information and experiences, and to create more favourable conditions in which to implement healthy city strategies. ${ }^{7}$ Since 1987 , WHO has enabled network coordinators to meet together regularly. Today, national

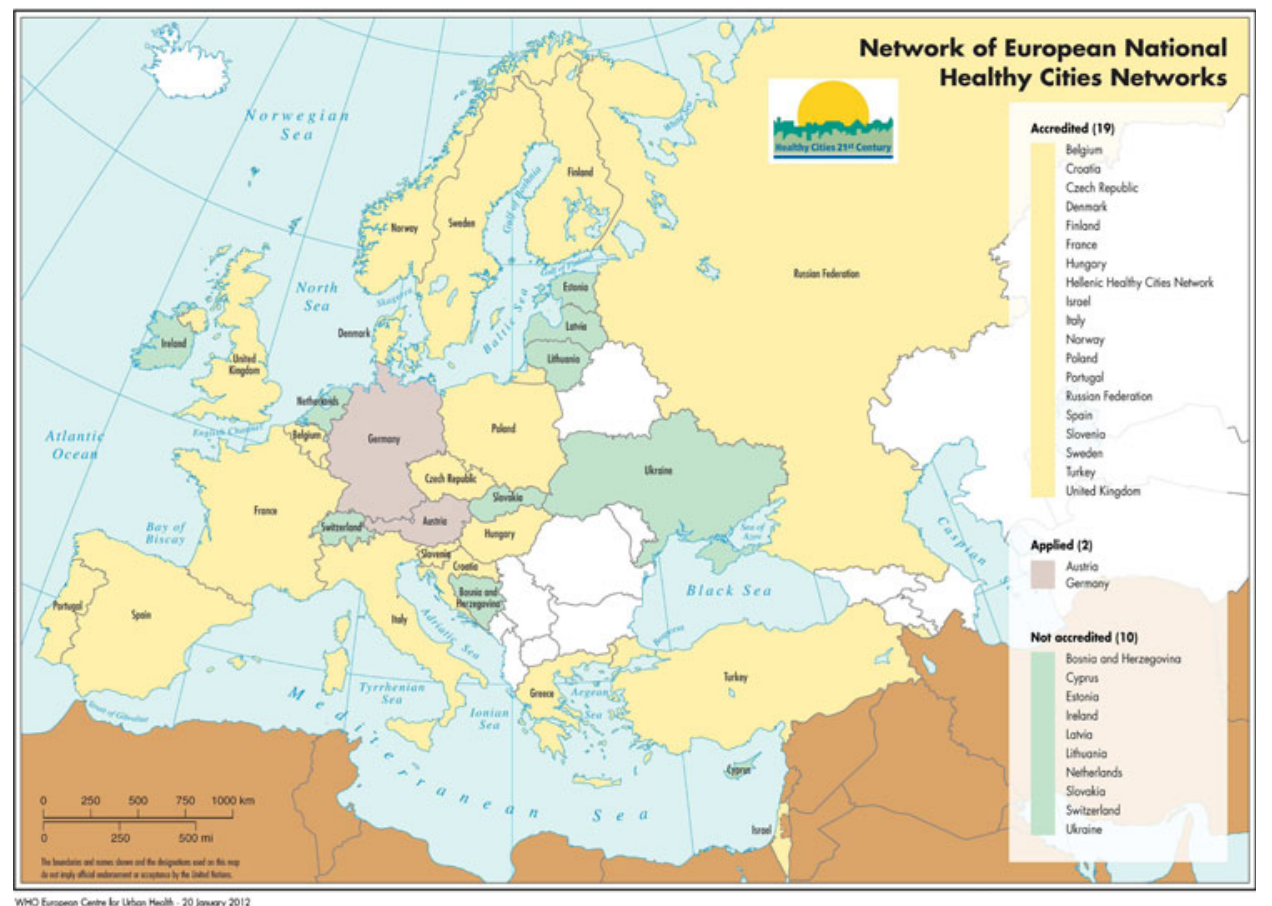

FIGURE 1. National health city networks in the WHO European region in January 2012. 
networks exist in most European countries (see Figure 1) and represent an estimated 1,300 city members. The European network that links the national networks together is known as NETWORK.

In 1997, a WHO survey revealed that national networks varied greatly in terms of their organisation, membership criteria and their access to and support from national governments, although they shared common aims and objectives. ${ }^{9}$ These aims include supporting member cities by enabling access to new public health information, to represent cities at a national level and to expand knowledge about the principles of healthy cities. Reaffirmed in 2009, WHO and national network coordinators have adopted a set of common criteria for national networks and their member cities following a process of close collaboration. These criteria are a set of standards which reflect of the best practice of national network organisation. They contain minimum criteria for the network's structure as well as for that of member cities. ${ }^{10}$ They allow networks, which reflect the diversity of their respective cultures, national policy contexts, local government remits and health challenges, to jointly raise standards in promoting healthy cities in Europe. WHO accredits those networks which meet these minimum standards.

The aim of this article is to review the outcomes and impact of national networks at the local through to the international level. First, it is necessary to distinguish intended outcomes - the diffusion of knowledge-from the wider impact on healthy cities. A hypothesised sequence is elaborated in the next section on methodology. It is informed by principal-agent theories. Dunlop ${ }^{11}$ identifies epistemic agents seeking to inform the policy community of principals, in our case the professionals and politicians who form city administrations and manage their intersectoral partnerships. Drawing on this theoretical framework, successful outcomes for an epistemic public health community are not health outcomes, but rather gauged by their influence on the policy community. Positive impacts on population health are assumed to follow from policies and programmes based on a healthy cities approach, but they take time to materialise ${ }^{12}$ and are not addressed here. Reviewing the Europeanization of health policies, Steffen and associates highlight the intellectual influence of a transnational epistemic community on shared health policies, frameworks and beliefs within the European Union. ${ }^{13}$ Mukherjee and Ekanayake measure the success of the epistemic community centred on the Global Alliance against Tobacco Marketing by WHO's adoption of The Framework Convention on Tobacco Control. ${ }^{14}$ Similarly we assess the outcomes of NNs not by their impact on the population health of member cities, but by the extent to which they encourage city administrations to adopt a healthy cities approach. The article then reviews the wider impact of NNs on city level, national and European policies.

\section{METHOD}

The framework for the review is based on a diffusion model of an epistemic community and summarised in Figure 2. The healthy cities approach to public health had its origins in WHO's elite epistemic community and we question first if this nexus of expertise continues to influence NNs (pathway "a" in Figure 2). Our primary outcome of NNs is the extent to which, as epistemic agents, they encourage city administrations to adopt and maintain a healthy cities approach to their population health (pathway "b"). This our second review question. The third question is the NNs wider impact on the objectives and policies of national 


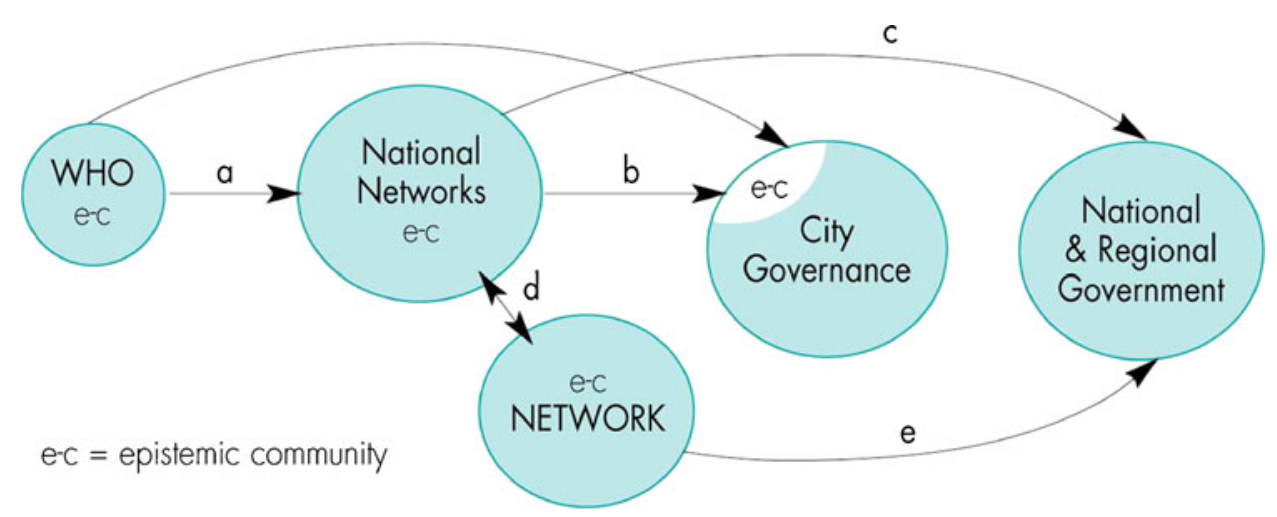

FIGURE 2. Model of epistemic diffusion of healthy city principles.

governments ("c"). Fourth, as covered in our companion article $^{2}$ on an earlier phase, we review NN activities which secure and maintain a healthy cities approach.

The evidence for this review is synthesised from two primary sources and is compared with the reviews of previous phases, cited earlier in this article. Data for Phase IV was accessed first from summary reports of NN returns to WHO in the form of an annual reporting template (ART). The ARTs questions cover priorities, network infrastructure and activities, political changes, national partnerships, obstacles and facilitative factors. A total of 20 networks replied to the June 2006 ART, ${ }^{15} 21$ in July 2007, ${ }^{16}$ and 14 networks in August 2008. Data presented in this article is sourced from all national networks, with a focus on 14 networks (a core group) who replied to all 3 years of the ART. The core group of networks are: francophone Belgium, Croatia, Czech Republic, Finland, France, Hungary, Israel, Norway, Poland, Portugal, Russia, Slovenia, Spain and Turkey.

A second source of data is coordinators' response to a general evaluation questionnaire (GEQ) distributed in 2008, at the end of the phase IV to 29 NNs. A combination of quantitative and qualitative questions asked national networks to describe case studies, learning from other networks, and their impact on member cities and national/ regional government. Politicians were asked to include a statement on added value, influence and potential. The demanding requirements of the questionnaire probably accounted for the low response rate. Thirteen NNs replied, overlapping the 14 consistently completing the ARTs (see list above) minus France. The core group of 14 networks form the majority of 19 NNs accredited by WHO by 2012 (Figure 1). Accredited networks meet four criteria: in summary, an endorsement of principles and strategies; a formal administrative infrastructure; products and outcomes and promoting active networking between members. Limited data from NNs which are not accredited or were non-responders to the general evaluation questionnaire mean that our overview is partial.

\section{RESULTS}

Results are divided into three sections: (1) outcomes as gauged by the influence of the epistemic community, via NNs, on city administrations; (2) the functions and organisation of NNs which encourage city administrations to adopt a 'healthy cities' approach to population health, and (3) the wider impact of NNs on the national and European policy communities. Reviews of earlier phases have analysed how NNs 
developed and expanded. This review of phase IV analyses a process of maintaining mature but sometimes fragile organisations.

\section{Outcomes}

Conceptual Figure 2 summarises a two-stage process for securing an outcome: first (pathway 'a') the epistemic community which originated in the nexus of WHO experts is expanded and maintained by the creation and development of NNs; then (pathway 'b') NNs influence city administrations to adopt a healthy cities approach to enhancing the health of their populations. A measure of success of stage 1 is the number and quality of NNs in Europe. A measure of success of stage 2 is the number of cities adopting and maintaining a healthy cities approach and the quality of their commitment.

The 2008 study identified 25 NNs as active; this is less than in 2003 but the criteria for 'active' were stricter. Based on WHO's 'Terms of Reference 2006-2008 ${ }^{17}$ we only classified a network as 'active' if it had a focal person/coordinator supported by a formal management structure such as a steering committee; a number of member cities (other than WHO designated cities); and at least one meeting or activity during the last 12 months. WHO recognised 31 NNs of which 19 are accredited by WHO (Figure 1). The accredited networks are amongst the 'active' networks identified in 2008. Criteria for accreditation, summarised earlier, refer to the quality of the organisation and crucially to the formal adoption of healthy cities 'principles and strategies,' a critical measure of the influence of the WHO epistemic community.

Second-stage outcomes can be gauged by membership of NNs. In most countries, membership requires the payment of an annual fee, suggesting the cities must value the service they receive. Figure 3 indicates how city membership in the NNs expanded during phase IV (2003-2008), with membership increasing in all but 1 of 20 countries. The Czech Republic had the biggest proportionate increase, from 34 to 85 member cities, Spain increased from 62 to 140 and the Turkish NN increased membership from 23 to 45 cities.

Successful outcomes are measured not only in numbers but also by the quality of network membership. All of the core group of NNs are accredited by WHO whose criteria relate not only to the NN organisation but also to member cities. Recommended criteria cover city organisation and, critically, a city council resolution adopting healthy cities principles, a second-outcome measure of the epistemic community. Of member cities of the active non-accredited NNs, we are less certain; though adopting a healthy city label strongly implies adopting some if not all healthy cities principles.

\section{Function of National Networks}

Of the 12 key functions of National Networks identified by Lafond and her associates, ${ }^{7}$ diffusion of knowledge remains their primary rationale. The core NNs form a 'grounded' epistemic community, infusing a continuing flow of knowledge from the WHO elite and pooling it with local realities 'to identify effective approaches for tackling the determinants of health in a country's urban areas'. Responding to the general evaluation questionnaire, the deputy mayor of Ishevsk summarised a process 'from contemplation to utilization of healthy cities methods.' Sharing knowledge of 'local realities' encourages a sense of solidarity between cities, making them more receptive to new approaches to public health. 


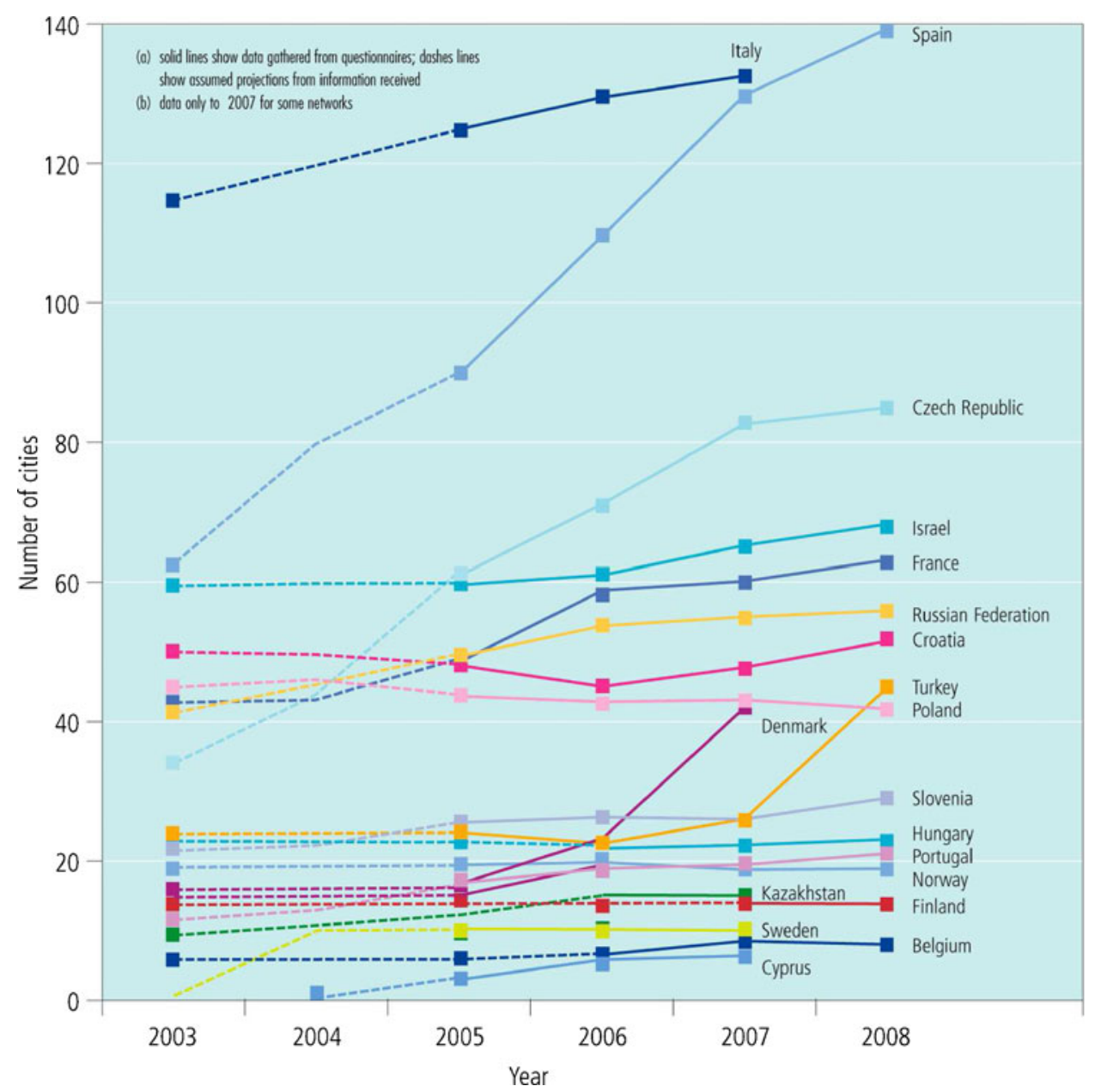

FIGURE 3. City membership of core NNs (2003-2008). Solid lines show data gathered from questionnaires; dashes lines show assumed projections from information received. Data only to 2007 for some networks.

Almost all respondents to the General Evaluation Questionnaire agreed there was added value from WHO and other NNs in giving strategic direction, and capacity to work on the core themes of phase IV (12 of 13 responses). Indeed, a strategic approach distinguishes phase IV, with many networks citing city health development profiling and planning, promoted by WHO as a dominant theme in phase III and a priority in phase IV. A core function of any healthy city network is to increase awareness of the social determinants of health among local level actors and to support them to produce integrated health profiles and plans to address poor health effectively. Poland reported $80 \%$ of its members' health activities were now based on a local health strategy rather than ad hoc actions. The Hungarian network supports members who wish to prepare their city health development plan using a health impact assessment method. Network funding must be matched by a financial contribution from the member city and over $30 \%$ have such plans. The Slovenian $\mathrm{NN}$ introduced a new urban health indicators system which is obligatory for all full members. 
Most NNs refer to the core themes which WHO introduced into phase IV to provide a more grounded approach to city development. For example, Hungary used case study presentations on healthy urban planning. The Polish network funded a grant competition on any other core theme, Healthy Ageing. The Italian and Slovakian networks adapted methodologies for Health Impact Assessment and rolled them out nationally. Finland and Turkey provided training for members on all core themes: healthy urban planning, healthy ageing, health impact assessment and the promotion of an active lifestyle. These specific applications of the four themes are informed by a wider analysis. Norway's Ministry of the Environment was one of the founders of their network, leading to a broad definition of health. The network developed a profile which surveyed both health and environmental factors. The focus on the broader determinants of health has enabled cities to produce comprehensive solutions to local problems. Croatia's network has prioritised the problems which cause the heaviest burden to local communities and the solution of which can most contribute to improving their quality of life. These include family, (unemployment, environment, urban planning), children and young people (free time, risky behaviour prevention, development of volunteering), society democratisation, mental health, adequate elderly care, improving quality of life of people with disabilities, and community safety. Spain has wide aims to promote work around health behaviours as well as immigration and health, poverty reduction, inequalities in health and citizen participation.

Networks provide valuable formal and informal learning opportunities. Organising conferences and training events to enable members to share experience remain an important function of the networks. During July 2007, 7 of the 21 networks held one or two conferences and another 10 networks held three or more. This volume of activity appears to remain constant over the years. The most frequent topics for these events are health inequalities, urban planning and health impact assessment. An ambitious training programme has been the Israeli network's 6 month course for health city coordinators in 2002 which was repeated in 2007. It was $120 \mathrm{~h}$ long and provided a mixture of theory and practical tools. The course has had the additional outcome of creating a highly supportive group of coordinators that continue to work together after the training period ended.

\section{Organisation of National Networks}

The core group of 14 probably represents, certainly includes, NNs which were relatively successful in performing the primary function of epistemic agent. Of the 12 who responded to a general evaluation question 'Is your NN now in a stronger position overall compared with 2003?', four strongly agreed and seven agreed, with one neutral. Lafond and associates ${ }^{7}$ earlier identified four factors which provide the basis for an effective, viable organisation critical to the success of networks. First, all the core group of NNs have a formal organisational structure. The general assembly of network members is usually the main decision-making body. Management is by a steering committee. Many networks have the status of a legal association with a treasurer or audit committee. As a legal entity, the national network can apply for project funding from a range of national and international sources.

Second is political leadership. Politicians have a key role in the general assemblies of NNs, convey legitimacy, and as it is evident from their statements embedded in the GEQ, enlarge the grounded epistemic community. There is evidence of blurring the distinction between technicians or professionals as epistemic agents and politicians as principal actors. NN politicians adopt an epistemic role in promoting 
a healthy cities approach; a technical group may, according to the Portuguese NN, provide 'leadership, dynamism and cohesion.'

Third is coordination and resources. The secretariat for the majority of networks is based in a member city, with the city coordinator and politician organising both the city level and national network activities. A minority are managed by national bodies such as a public health school. Approximately $2 / 3$ of networks have membership fees. However, resource constraints feature frequently in the evaluation reports. Sixty percent of NNs surveyed in July 2007 identified insufficient human and financial resources as important obstacles to achieving all their goals. When networks can access funding for coordination, rather than only relying on the enthusiasm of volunteers, they can achieve more significant outcomes. Whereas the loss of central government funding for the Norwegian NN restricted activities in 2008, the Czech Republic NN expanded to employ nine staff using a business model based on project income mainly from the European Union. This resource stabilised the whole network and increased the influence of healthy cities throughout the Czech Republic, membership doubled to 85 cities. However in 2010, the network was also obliged to reduce the number of full time staff.

Fourth is internal evaluation of NN activity which increased from a low baseline in 1999 to cover a quarter of networks by 2003 to two thirds (9 of 14) by 2008. The Israeli network published their evaluation of 18 active healthy cities members. ${ }^{18}$ The cities were assessed on six criteria (see Figure 4). Political support, together with the coordinators' building capacity, was found to be significant facilitators for sustaining successful healthy cities policies. Overall, the evaluation found that environmental protection was rather weak and needed to be incorporated into future training sessions.

An evaluation of the implementation of the healthy cities programme across Germany found that although the network had expanded rapidly, greater integration is required within the local political administrative system ${ }^{19}$

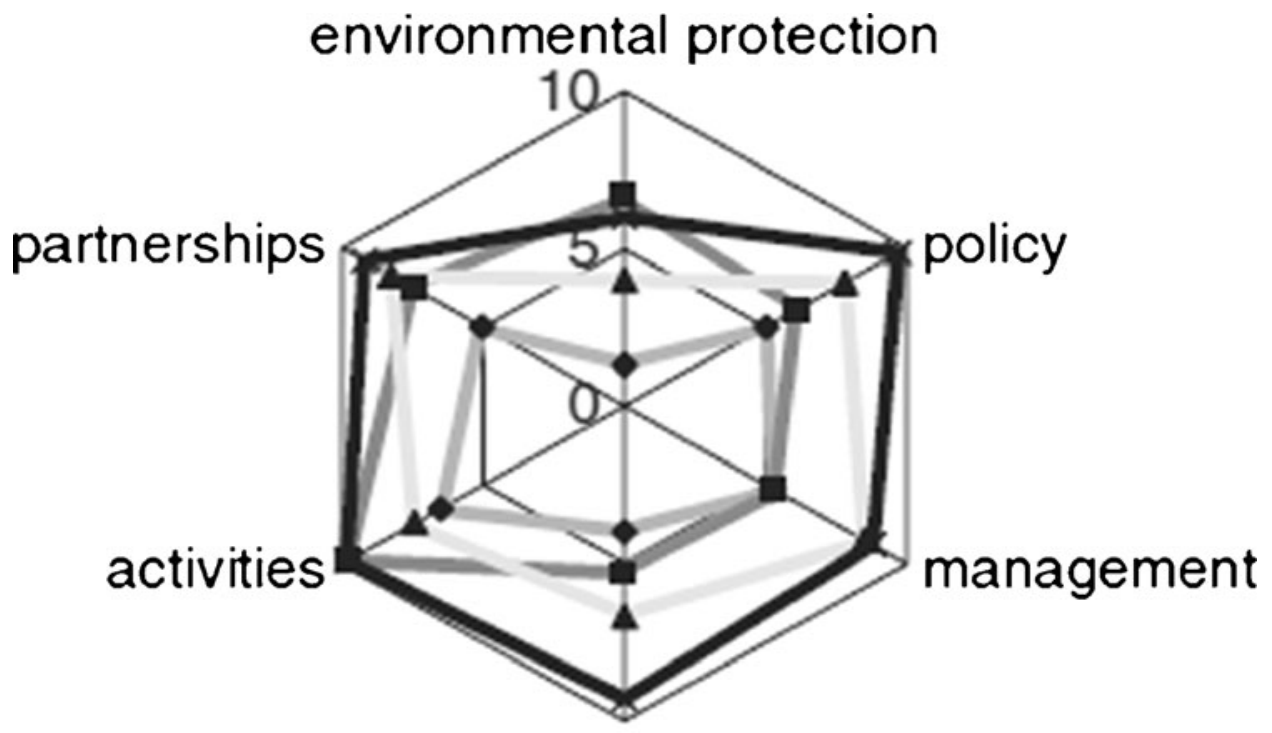

\section{community participation}

FIGURE 4. Israeli cities were compared using six dimensions of healthy cities ${ }^{18}$ (p. 269). 
Evaluation appears to have generated a fifth success factor; strategic direction. Compared to the late 1990s, networks appear to be better organised with clearer strategies and annual plans. In July 2007. ${ }^{16}$ Sixty percent of 21 networks reported having a formal network strategy document, increasing to over $70 \%$ by 2008 . The Portuguese NN reported how their first strategic plan, approved in 2003 helped to consolidate their network. Its internal organisation would be further strengthened by its second strategic plan with objectives for 2008 to 2013. The new model of operating sought to overcome difficulties resulting from the geographical dispersion among the municipalities, as well as encouraging a mentoring system between the more and less experienced municipalities. Another objective involved raising the criteria for joining the network, requiring the production of a profile and a health development plan. The training of the technical staff and politicians remained a priority. The Portuguese training events were inspired by the courses organised in Israel.

\section{WIDER IMPACTS}

NNs have a wider impact (pathway ' $c$ ') influencing the policy of higher tiers of their regional and national governments and forming horizontal coalitions with sister networks (pathway 'd') across the European Region. In 1997, a third of networks were developing regional activities ${ }^{9}$; 10 years later, there is evidence of NNs maintaining their influence especially on autonomous regional and county governments in Spain, Belgium, Norway and Croatia. They influence policies of national governments either by strengthening the public health aspects of Health Ministries normally focused on health care services or injecting a health dimension into the work of other government departments. Examples of the former are the Spanish NN's contribution to the design and implementation of the Ministry of Health's 'Nutrition, physical exercise and prevention of obesity programme:' the Slovenian NN's influence in adding a healthy cities perspective to the National Public Health Plan 2003-2010, the Portuguese NN's contribution to the wider determinants of health in the Portuguese National Health Plan (2004-2010); and the French network's study on the health of travelling people. Examples of influence on nonhealth ministries are the Czech NN's contribution to the transport and energy components of their government's Council for Sustainable Development and the Norwegian NN's injection of a stronger public health dimension into a report of the national assembly on 'The future of the Regions.'

At a pan-European level, it is evident from the General Evaluation Questionnaire that a majority of the core group value their contact with WHO and other NNs. Eleven (of 12) respondents agree or strongly agree that it has added value. Similar proportions agree that it has improved strategic direction, local political commitment and legitimacy at a national level. Some NNs have formed small consortia to diffuse knowledge, for example, Spain with Italy, Israel with Portugal and Russia, Germany with Slovenia and Austria, and France with the Francophone provinces of Belgium and Switzerland.

Whereas only a minority of core group NNs (three of 12 GEQ respondents to this question) perceive the WHO connection as attracting more funding, European Union co-funding is used extensively for projects covering topics such as active living, urban health indicators, profiles, HIV and mental health. ${ }^{15}$ Thirteen networks reported pan-European projects or partnerships with international organisations in July $2007,{ }^{16}$ primarily funded by the EU. Though NNs often facilitate consortia of 
member cities, HEPRO (Health and Environmental Programme) is a prime example of their direct involvement, involving 32 partners from eight countries including the NNs of Denmark, Poland and Norway. Over a 3-year period, HEPRO aimed to improve municipal public health planning. Via site visits and learning conferences, it developed tools for integrative and communicative planning, a process involving local people. Based on the Norwegian Health and Environmental survey, a total of 45,000 people in eight countries were asked to provide information which was fed into the planning process.

\section{DISCUSSION}

Our review reveals mature national healthy cities networks in most European countries, generally sustaining their primary role of epistemic agents. Though lack of data prevents a comprehensive overview of the number, membership and effectiveness of all NNs, it is evident that a core group of 14 accredited NNs is effective in pooling new evidence generated by WHO (pathway a, Figure 1) with local realities and diffusing it to member cities (pathway b). It is evident too that NNs have evolved organically rather than simply as agents of WHO. In the formal document for accrediting $\mathrm{NNs}, \mathrm{WHO}^{20}$ defines its roles as 'to provide leadership and strategic support to the Network of European National Healthy Cities Networks.' In reality, WHO has limited resources to provide organisational and strategic support to NNs. The badge of legitimacy and the generation of knowledge are WHO's most significant contributions.

In the core group, there is evidence of a more systematic links between NN organisations and member cities (pathway b). Broesskamp-Stone ${ }^{21}$ describes successful networks as first allowing an exchange between network members, then concerted action will occur, finally attaining a stage of joint production. If these three levels of increasingly cooperative actions are applied to the healthy cities movement, then the evaluations since 2006 show that all the national networks encourage information exchange via working groups, web sites and newsletters. At least half of the NNs appear to be at the highest level where the members jointly produce strategies and training events.

Though there is evidence of increasing $\mathrm{NN}$ impact on national governments (pathway c) and in forming cross-border coalitions to access European expertise and EU funding, NETWORK (the European network of NNs) has yet to fulfil its full potential for knowledge diffusion and solidarity (pathway $\mathrm{d}$ ). When reviewing tobacco-control networks, Mueller et al. ${ }^{22}$ found that frequent communication amongst network partners created more productive relationships. NETWORK productivity could be enhanced by greater communication via physical, telephone or web-based meetings. WHO could enhance cross-border learning and possibly lead applications for EU funding to support specific projects. It could also be possible to develop a role to review and advise national governments (pathway e) on European public health policy produced by WHO or the EU.

Epistemic communities 'come and go'23 and networks occasionally stop functioning; others reform and new ones are created. ${ }^{21,24}$ Though this review has identified 14 core NNs which have sustained their activity, overall there are slightly fewer active healthy city networks in Europe in 2008 compared to 2003. This is may be due to the stricter definition of an active network used in this paper as the total number, including those going through a period of transformation or for which we have no recent information, is stable. Further information is needed to ascertain the 
direct cause of the decrease in active networks. However, previous evidence has shown that NNs are affected by the loss of leadership from a key member city or individual or unfavourable changes in political support or national policies. ${ }^{9,15}$ The overall increase in the number of members amongst the active NNs shows that they are having a growing impact with more cities becoming aware of healthy city policies. A dilemma for NNs is to increase their membership whilst ensuring that the cities' activities are of a high standard. The emphasis NNs are placing on encouraging cities to have profiles of their populations and to have health plans or strategies is a positive way to ensure quality at a local level.

Our review confirms the salience of the four critical success factors identified by Lafond and associates in enhancing a network's efficacy. First is an organisation which is structured according to WHO accreditation criteria. Though a bottom-up approach may better reflect members concerns, ${ }^{25}$ a top-down hierarchical network based on formal institutional alliances (with national agencies or governments) can better facilitate coordination and attract more funding-the second critical success factor. Third, as Stone ${ }^{26}$ has stressed, successful policy development is far more likely to occur in those networks that involve decision makers. A strong commitment from local politicians is key to the successful development of a national healthy city network. The number of networks reporting at least adequate political commitment from city politicians is regularly over $80 \%{ }^{15,16}$ Networks need to ensure that politicians make the strategic decisions and they have sufficient technical staff to implement the decisions.

Evaluation, the fourth critical success factor identified earlier by Lafond and associates, is strongly linked in this review to the development of more strategic NN programmes. As O'Neill and Simard ${ }^{27}$ have discussed, it is essential to evaluate Healthy Cities even if there is no agreement on a standard set of indicators. They feel that the process of evaluation involving making negotiated choices, is in itself a learning opportunity. The number of networks evaluating their work is increasing but evaluation is not yet universal. A role for WHO and NETWORK could be to provide training and/or tools to help NNs evaluate their own impact and that of their members.

\section{CONCLUSION}

This article has reviewed the European National Healthy City Networks, with a particular focus on a core group of 14 WHO-accredited NNs, who responded to a series of evaluation questionnaires. The methodological challenges of evaluating the performance of the healthy cities are highlighted by both Green and Tsouros ${ }^{28}$ and De Leew. ${ }^{29}$ As Jansen et al. ${ }^{30}$ showed, it is not easy to demonstrate that successful collaboration contributes to enhanced population health. However by focusing on NNs as epistemic agents, this review has been able to identify real contributions by national healthy city networks to improving local public health structures and processes.

It is clear that without the national healthy city networks working throughout the WHO European region, there would not be an estimated 1,300 cities that have made a commitment to work on healthy cities priorities. This is the most significant outcome and the primary measure of success. NNs also have an impact at national level. This paper contains examples of NNs being commissioned to provide training and of influencing national public health programmes. However, this potential to act at national and in particular, at a European level is not fully developed and our 
paper suggests ways in which national health city networks effectiveness could be further enhanced.

\section{ACKNOWLEDGMENTS}

The authors wish to thank all the network coordinators who kindly participated in the study and Leah Lafond who significantly contributed to development of this paper.

\section{REFERENCES}

1. Kickbusch I. The contribution of the world health organization to a new public health and health promotion. Am J Public Health. 2003; 93(3): 383-388.

2. Lafond LJ, Heritage Z. National networks of Healthy Cities in Europe. Health Promot Int. 2009; 24(S1): i100-i107.

3. Haas PM. Introduction: epistemic communities and international policy coordination. Int Organ. 1992; 46(1): 1-35.

4. Schneider $\mathrm{CH}$. Global health and international relations: pressing issues, evolving governance. Aust J Int Aff. 2008; 62(1): 94-106.

5. WHO Regional Office for Europe. (1998) HEALTH21: Health for All in the 21st Century. WHO Copenhagen.

6. Dooris M, Heritage Z. Healthy Cities: facilitating the active participation and empowerment of local people. J Urban Health. 2011. doi:10.1007/s11524-011-9623-0.

7. Lafond LJ, Heritage Z, Tsouros A, Farrington J. National healthy cities networks: a powerful force for health and sustainable development in Europe. Copenhagen: WHO Regional Office for Europe; 2003.

8. Goumans M (1992) What about healthy networks? An analysis of structure and organisation of national healthy cities networks in Europe. Maastricht, Research for Healthy Cities Clearing House (RHC Monograph Series No. 3)

9. Farrington J. The state of national networks for healthy cities. Copenhagen: WHO Regional Office for Europe; 1997.

10. WHO Regional Office (2009) Terms of Reference and application for accreditation for membership in the Network of European National Healthy Cities Networks in Phase V (2009-2013) World Health Organization

11. Dunlop C. Epistemic communities and two goals of delegation: hormone growth promoters in the European Union. Sci Public Policy. 2010; 37(3): 205-207.

12. Draper R, Curtice L, Hooper J, Gourmans M. WHO healthy cities project: review of the first five years (1987-1992): a working tool and reference framework for evaluating the project. Copenhagen: WHO Regional Office for Europe; 1993.

13. Steffen M, Lamping W, Lehto J. Introduction: the Europeanization of health policies. In: Steffen M, ed. Health governance in Europe: issues, challenges and theories. Oxon: Routledge; 2005.

14. Mukherjee A, Ekanayake EM. Epistemic communities and the global alliance against tobacco marketing. Thunderbird Int Bus Rev. 2009; 51(3): 207-218.

15. WHO. Annual reports (ART) - analysis of results. National healthy city networks (2005/ 6) Turku business meeting. Copenhagen: WHO Regional Office for Europe; 2006.

16. WHO. Analysis of annual reporting by national networks (2006/7) Rennes business meeting. Copenhagen: WHO Regional Office for Europe; 2007.

17. WHO. Action framework and terms of reference (2006-2008)-network of the European national healthy cities networks. Copenhagen: WHO Regional Office for Europe; 2006.

18. Donchin M, Shemesh AA, Horowitz P, Daoud N. Implementation of the healthy cities' principles and strategies: an evaluation of the Israel Healthy Cities Network. Heal Promot Int. 2006; 21(4): 266-273. 
19. Plumer DP, Kennedy L, Trojan A. Evaluating the implementation of the WHO healthy cities programme across Germany. Heal Promot Int. 2010; 25(3): 342-54.

20. WHO. Strategy and action plan (2006-2008) - network of the European national healthy cities networks. Copenhagen: WHO Regional Office for Europe; 2006.

21. Broesskamp-Stone U. Assessing networks for health promotion: frameworks and examples. Münster: University Bielefeld; 2004.

22. Mueller N, Krauss M, Luke D. Interorganization relationships within state tobacco control networks: a social network analysis. Prev Chronic Dis. 2004; 1(4): AO18.

23. Eyles J, Robinson K, Elliot S. An epistemic community comes and goes? Local and national expressions of heart health promotion in Canada. BMC Heal Serv Res. 2009; 23(9): 35.

24. Schweyer FX, Levasseur G, Pawlikowska T. Créer et piloter un réseau de santé: Un outil de travail pour les equipes (translation) creating and running a health network: a tool for team members. Rennes: Éditions de l'École nationale de la santé publique; 2002.

25. Thomas P, Graffy J, et al. How primary care networks can help integrate academic and service initiatives in primary care. Ann Fam Med. 2006; 4(3): 235-239.

26. Stone, D. (2001) Learning Lessons, Policy Transfer and the International Diffusion of Policy Ideas.: Centre for the Study of Globalisation and Regionalisation, Univ of Warwick, UK http://www2.warwick.ac.uk/fac/soc/csgr/research/workingpapers/2001/ wp6901.pdf

27. O'Neill M, Simard P. Choosing indicators to evaluate healthy cities projects: a political task? Heal Promot Int. 2006; 21(2): 145-152.

28. Green G, Tsourus A. Evaluating the impact of healthy cities in Europe. Italian J of PH. 2007; 5(4): 255-260.

29. De Leeuw E. Do healthy cities work? A logic of method for assessing impact and outcome of healthy cities. J Urban Health. 2011. doi:10.1007/s11524-011-9617-y.

30. Jansen MJ, DeVries NK, et al. Collaboration between practice, policy and research in local public health in the Netherlands. Health Policy. 2008. doi:10.1016/j.healthpol.2007.11.005. 